\title{
Clinical trial design for cutaneous neurofibromas
}

Ashley Cannon, PhD, MS, CGC, Kurt Jarnagin, PhD, Bruce Korf, MD, PhD, Brigitte C. Widemann, MD, Denise Casey, MD, Hon-Sum Ko, MD, Jaishri O. Blakeley, MD, Sharad K. Verma, PhD, and Dominique C. Pichard, MD

Neurology ${ }^{\circledR}$ 2018;91 (Suppl 1):S31-S37. doi:10.1212/WNL.0000000000005790

\section{Abstract}

\section{Objective}

Several clinical trials targeting cutaneous neurofibromas (cNF) have been conducted; however, none has resulted in meaningful changes to care. The Clinical Trial Design and Development subgroup's goals were to (1) define key considerations in the design of clinical trials for cNF, (2) summarize existing data in relation to these considerations, and (3) provide consensus recommendations about key elements of trial design to accelerate the clinical development of therapies for $\mathrm{cNF}$.

\section{Methods}

The subgroup, with experts from genetics, dermatology, neurology, oncology, and basic science, spanning academia, government research, and regulatory programs, and industry, reviewed published and unpublished data on clinical trials for $\mathrm{cNF}$ and other diseases in the skin. Discussions of these data resulted in formulation of a list of priority issues to address in order to develop efficient and effective clinical trials for cNF.

\section{Results}

The subgroup identified 2 natural history studies of cNF, 4 priority outcome measures, and 6 patient-reported outcome tools for potential use in efficacy trials of cNF. Time to initiate intervention, patient eligibility, mechanism of action, route of administration, safety monitoring, and regulatory agency interactions were identified as key factors to consider when designing clinical trials for $\mathrm{cNF}$.

\section{Conclusions}

Alignment on endpoints and methods for the measurement and quantification of cNF represent a priority for therapeutic development for cNF. Advances in technological methods and outcome tools utilized in other skin diseases may be applicable to cNF studies. Patient age is an important factor guiding trial design and clinical development path.

\author{
Correspondence \\ Dr. Pichard \\ picharddc@nih.gov
}

\section{RELATED ARTICLES}

Creating a comprehensive research strategy for cutaneous neurofibromas

Page S1

Cutaneous neurofibromas: Current clinical and pathologic issues

Page S5

The biology of cutaneous neurofibromas: Consensus recommendations for setting research priorities

Page S14

Considerations for development of therapies for cutaneous neurofibroma

Page S21 


\section{Glossary}

cNF = cutaneous neurofibromas; HFUS = high-frequency ultrasound; NF1 = neurofibromatosis type 1; OCT = optical coherence tomography; PRO = patient-reported outcomes; $\mathbf{Q o L}=$ quality of life; SF = Short Form.

Cutaneous neurofibromas (cNF) are histologically benign tumors. Although these tumors are not lethal, they are associated with substantial morbidity due to disfigurement and severe effects on quality of life (QoL) for persons with neurofibromatosis 1 (NF1). A QoL survey completed by 128 adults with NF1 in France demonstrated that visibility of lesions negatively influenced emotions, physical symptoms, and functioning. ${ }^{1}$ Similar results were reported in Italian and US cohorts. ${ }^{2,3}$ These findings underscore the need for effective therapy and prevention. Other than procedural-based approaches, there are no drug therapies that have successfully altered the occurrence, progression, or size of cNF lesions. ${ }^{4}$ Given the severe morbidity of $\mathrm{CNF}$ in patients with NF1, the NF1 research community and NF1 advocacy groups have placed a high priority on developing therapies to reduce the burden of cNF. The Clinical Trial Design and Development subgroup presents the priorities and challenges associated with conducting clinical trials targeting $\mathrm{cNF}$ in NF1 patients. Our aspiration is that this information may enable clinical investigators, scientists, regulatory agencies, affected individuals, and their advocates to be better positioned to work together to accelerate the development of therapies for cNF.

\section{Methods}

The Clinical Trial Design and Development subgroup was composed of clinical and clinical science experts from academic, public agency, and private sector settings tasked with the review of published and unpublished materials pertaining to the conduct of clinical trials for $\mathrm{cNF}$ and other diseases in the skin (e.g., atopic dermatitis, psoriasis). Key topic areas including natural history, assessment methods for measuring tumors, functional endpoints, safety, regulatory interactions, and development strategies were discussed. The subgroup members reviewed the topic areas individually and as a group during a series of meetings facilitated over a 4-month period in order to prioritize key questions and establish consensus recommendations for each topic area.

\section{Results}

\section{Natural history}

The Food and Drug Administration rare disease guidance emphasizes the importance of defining the natural history of a rare disorder in order to guide clinical trial design and the development of therapies. ${ }^{5}$ Knowledge of disease course and characteristics is critical for selecting outcome measures and other important design elements in clinical trials. Unique challenges exist in the study of the natural history of NF1, including the small number of patients and the heterogeneous clinical phenotype. Most data on the natural history of cNF in patients with NF1 are based on retrospective studies. Recent efforts are addressing this gap and 2 prospective natural history studies on cutaneous manifestations of $\mathrm{NF} 1$ are ongoing. The first of these 2 studies measured the number and size of cNF lesions with calipers in 3 different body sites of 22 adults (median age 47.5 , range $38-70$ ) over 8 years. $^{6}$ Clinical assessments were performed at 4-month intervals for the first 2 years and then at 8 years from study entry. The data revealed an average monthly increase in volume of $0.37 \mathrm{~mm}^{3}$ for tumors located in the back region, $0.28 \mathrm{~mm}^{3}$ in the abdominal region, and $0.21 \mathrm{~mm}^{3}$ in the arm/leg region $(1.7 \%-2.7 \%$ volume increase per month). ${ }^{6}$ The mean number of new cNF lesions within the $100 \mathrm{~cm} 2$ study frames by body region developing over 8 years was 3.1 on the back, 1.7 on the abdomen, and 0.4 on the extremities. Involution was not observed. These data show that cNF lesions grow very slowly in adults older than 35 years, and that the rate of increase in number of cNF lesions varies by body region.

The second prospective study is the National Cancer Institute's natural history study of children and adults up to the age of 35 with NF1 (NCT00924196). In this study, the presence and number of skin manifestations related to NF1 (café-au-lait macules, cNF lesions, axillary/inguinal freckling) are monitored every 1-3 years. Data are still being collected. In addition to monitoring growth over time across the overall population of individuals with NF1, quantifying growth characteristics at different ages were identified as a key consideration for further defining the natural history of cNF. A population-based study conducted in Wales demonstrated that over $99 \%$ of adults with NF1 had cNF lesions and that the number of lesions increased with age. ${ }^{7}$ A subsequent cross-sectional study of 728 pediatric and adult patients with NF1 also showed that the number of cNF lesions increased with age (figure 1$).^{8}$ In addition to age, hormones and pregnancy have been hypothesized to influence the development of cNF. ${ }^{9}$

These studies provide a broad review of growth characteristics of cNF in children and adults with NF1. However, knowledge gaps remain, and they include (1) prospective data on the rate of appearance of various forms of cNF development and pattern of progression in children and young adults, (2) growth rates of nascent vs mature cNF tumors, (3) the influence of hormones or other growth factors on the development and proliferation of cNF tumors, (4) the rate of spontaneous involution, (5) identification of reliable biomarkers for cNF development, and (6) comparisons of measurement tools. Inconsistent definitions that have been applied to $\mathrm{CNF}$ pose a major limitation in generating natural 


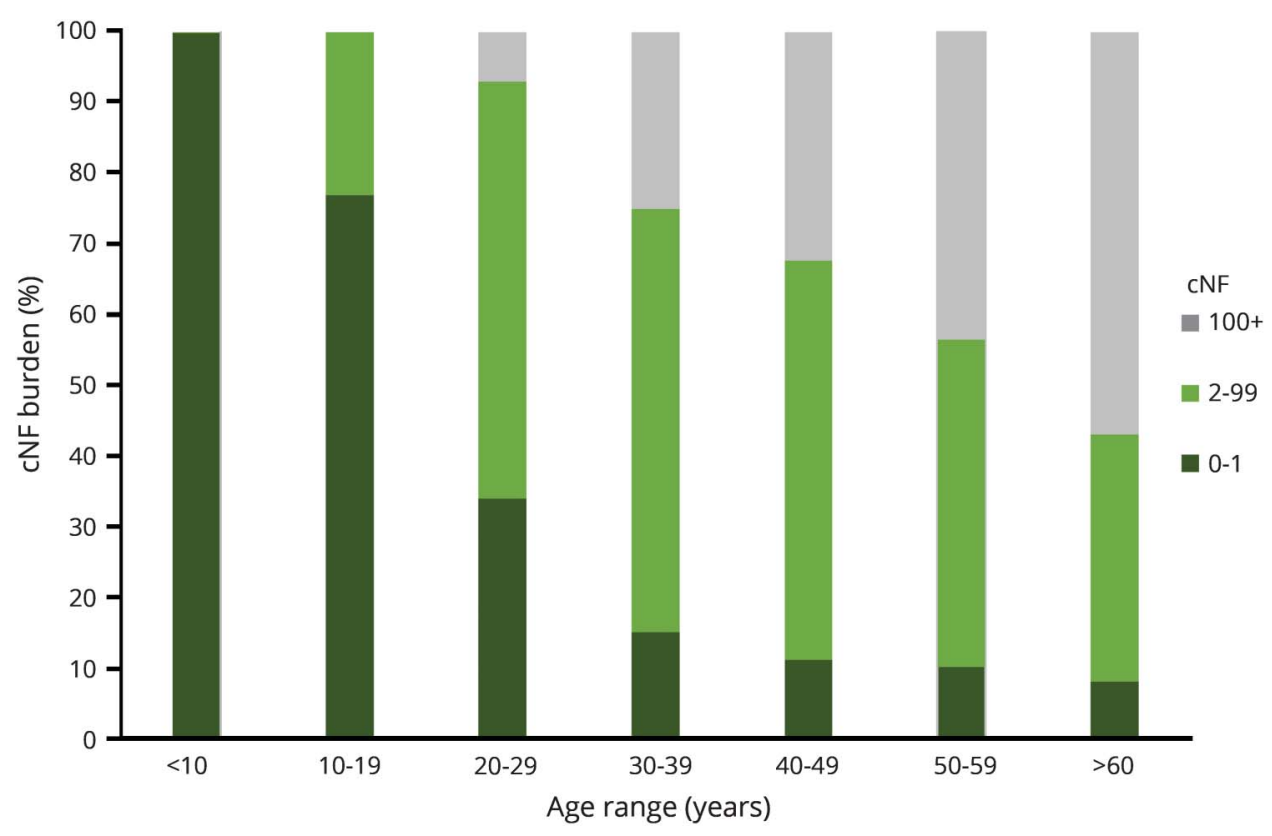

Adapted with permission from the Duong et al. ${ }^{8}$ cross-sectional study of 728 pediatric and adult patients with neurofibromatosis 1.

history data. ${ }^{10}$ It will be important to define consistent criteria for cNF (and possible subtypes) a priori and to clarify which tumor types should be measured with specific assessment tools within each study.

\section{Clinical trials and outcome measures}

Outcome measures are determined by the intended goals of the clinical trial. The cost, ease of use, accessibility, and reliability and reproducibility of the outcome measure are of paramount importance. Possible efficacy endpoints for trials in $\mathrm{cNF}$ are shown in table 1 , and include assessment of (1) tumor size, (2) number of tumors, and (3) patient QoL.

\section{Assessment of tumor number and size}

Measurement approaches that enable the collection of quantitative data about tumor growth are very important. The paper frame is a clinician-reported outcome measure used to quantify the number of cNF lesions (figure 2). ${ }^{11}$ A $100 \mathrm{~cm}^{2}$ paper frame is placed on the skin and all cNF lesions within the frame are counted. A caliper is used to measure lesion size. While the use of calipers in the evaluation of cNF size after treatment with the vascular endothelial growth factortargeting agent ranibizumab resulted in variable results, ${ }^{4}$ caliper measurement was used effectively with good reliability for the evaluation of cNF in an 8-year natural history study. ${ }^{6}$ The combination of calipers and paper frames represents a lowcost, accessible method to report the number and the size of cNF lesions in a limited area of the body. Disadvantages are the inability to detect or measure small lesions, the need for investigator experience and training, and the impracticality of measuring the whole body tumor burden when thousands of tumors are present. Initial data indicate that this approach captures change in tumor size, but cannot assess the size of small or flat tumors or portions beneath the skin surface.

New approaches, such as optical coherence tomography (OCT) or high-frequency ultrasound (HFUS), may assess the full thickness of a lesion above and below the skin surface.

Table 1 Priority cutaneous neurofibromas (cNF) trial outcome measures and endpoints for use in clinical trials of cNF

\begin{tabular}{|c|c|c|c|}
\hline Outcome measure & Trial endpoint & Method of measurement & Comment \\
\hline Tumor size & Reduction in cNF size & $\begin{array}{l}\text { Caliper, digital and volume } \\
\text { photography, ultrasound, MRI }\end{array}$ & $\begin{array}{l}\text { Likely that substantial reduction in size required to } \\
\text { be clinically meaningful }\end{array}$ \\
\hline Tumor number & $\begin{array}{l}\text { Decrease in the occurrence of } \\
\text { new cNF }\end{array}$ & Counting development of new CNF & $\begin{array}{l}\text { Requires long time to document due to unknown } \\
\text { natural history }\end{array}$ \\
\hline $\begin{array}{l}\text { cNF-related morbidity } \\
\text { (patient QoL) }\end{array}$ & $\begin{array}{l}\text { Improvement in pruritus, } \\
\text { emotional distress }\end{array}$ & PRO & $\begin{array}{l}\text { Difficult to attribute morbidity and improvement } \\
\text { with certainty to CNF }\end{array}$ \\
\hline
\end{tabular}

Abbreviations: PRO = patient-reported outcome; QoL = quality of life. 
Figure $2100 \mathrm{~cm}^{2}$ paper frame used as a guide to manually count and measure cutaneous neurofibroma (cNF) lesions

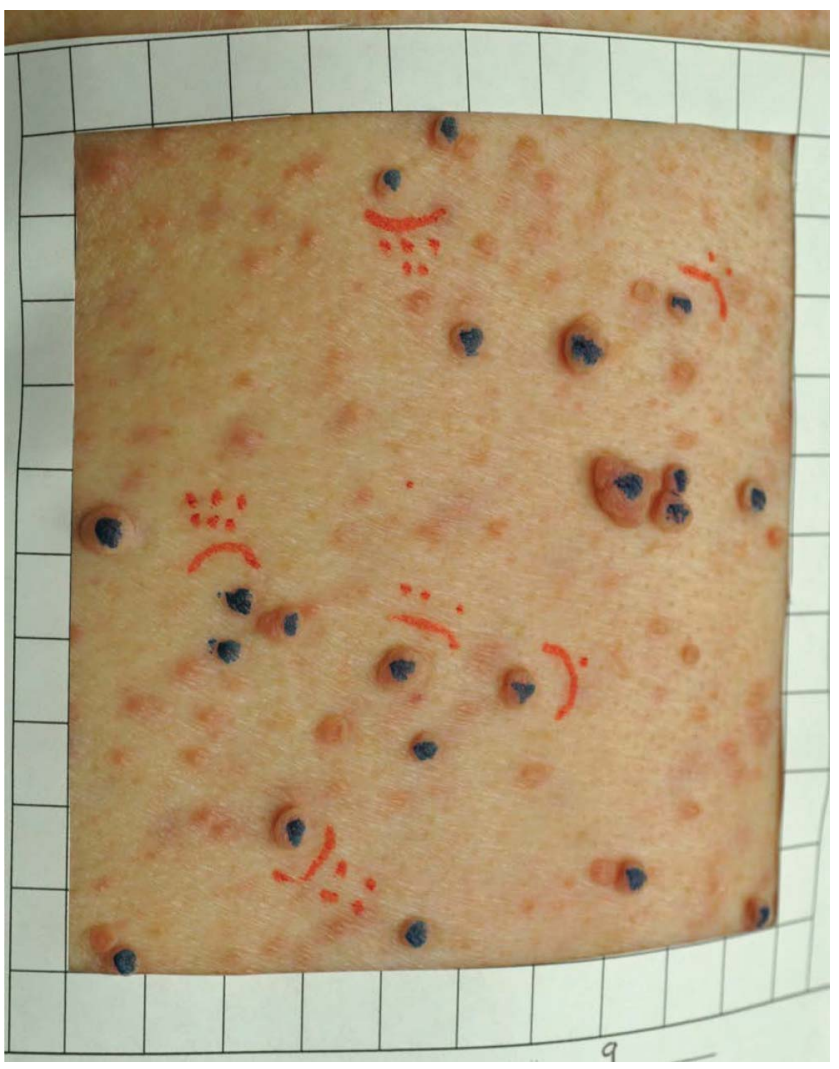

Blue indicates cNF lesions that were counted ( $>4 \mathrm{~mm}$ ). Red indicates the $\mathrm{CNF}$ lesions that were measured.

These procedures may allow a more sensitive measure of change over time or in response to therapy. ${ }^{12,13}$ The high resolution of these techniques may shorten the observation period and provide the opportunity to intervene earlier in the course of cNF development. OCT can provide a visualization of the full structure of normal human skin at a resolution of approximately $5 \mu \mathrm{m}$, enabling the visualization of sweat ducts, capillaries, and blood flow. However, nerve endings are under $2 \mu \mathrm{m}$ in diameter, which is below the resolution of OCT, so there are limitations with respect to visualization of some aspects of the $\mathrm{cNF}$.

HFUS is a painless, noninvasive technique that uses frequencies between 20 and $100 \mathrm{MHz}$ to provide increased resolution and improved visualization of structures and inflammation in the skin. HFUS has been used to measure tumors in the skin, such as basal cell carcinomas, and to aid in the surgical removal of basal cell carcinomas. ${ }^{14} \mathrm{~A}$ recent prospective study with the aims of (1) describing sonographic appearance of different types of cNF, (2) assessing interobserver agreement, and (3) associating clinical and ultrasound features evaluated $108 \mathrm{cNF}$ lesions in patients with NF1 with a $25-\mathrm{MHz}$ HFUS. ${ }^{13}$ This study demonstrated consistent sonographic findings, including tumors being hypoechoic. The identification of a specific sonographic feature may avoid the need for a skin biopsy. This avoidance would be especially useful in children, where early diagnosis is more challenging. Additional studies need to be performed to validate the use of HFUS in this population.

Technological advances can address some shortcomings of existing quantification methods and other outcome measures that have been proposed. They include $2 \mathrm{D}$ or $3 \mathrm{D}$ volumetric photography, conventional ultrasound, and MRI. Conventional ultrasound and HFUS have been used to quantify the volume of individual cNF lesions (figure 3 ), but the inability to capture whole body burden remains. ${ }^{13,15}$ To address this limitation, a whole body imaging system that uses multiple cameras to simultaneously capture the entire body surface for 2D and 3D image analysis has been developed, but has not been applied to cNF to date. While tools such as conventional ultrasound, MRI, OCT, and HFUS offer the potential for rapid and enhanced sensitivity of quantifying tumor size and measuring tumor growth on an accelerated time scale, the cost and training required to use these devices need to be considered. Clinical trials in rare diseases often require participation of multiple sites, and costly devices or substantial training requirements may pose barriers for such trials.

Clinically meaningful outcomes may not necessarily be captured with the assessment of tumor size or number alone. Complete resolution of cNF or dramatic reduction in size may be representative of clinical benefit for patients; however, more modest partial reductions in tumor burden have less clear meaningful clinical benefit. In general, tumor size reduction that correlates with reduced pain or discomfort or improved function would provide more supportive evidence of clinically meaningful effectiveness.

In addition to the assessment tools to objectively measure change in cNF size, an ordinal global assessment scale, such as the Investigator Global Assessment or the Physician Global Assessment, should be considered for the study of cNF in NF1. Properly designed global assessment scores are acceptable as outcome measures for establishing primary endpoints in clinical trials for some dermatologic conditions, ${ }^{16}$ such as atopic dermatitis, psoriasis, and acne. Global assessments have also been used in studies for infantile hemangioma, ${ }^{17}$ which is also not life-threatening, but does result in disfigurement and functional deficits, and has a negative influence on the patient's psyche. Such global assessment scales should be based on a limited number of levels describing the skin condition under study, and not on changes from an arbitrary time point such as baseline. Differences between global assessment scales for a specific condition underscore the need for standardization among investigators within the field such that data may be compared across studies. ${ }^{16}$ Currently, there is not a global assessment scale for $\mathrm{cNF}$, and thus development of such a scoring system is an unmet need for clinical research in this area. 
A. Normal skin

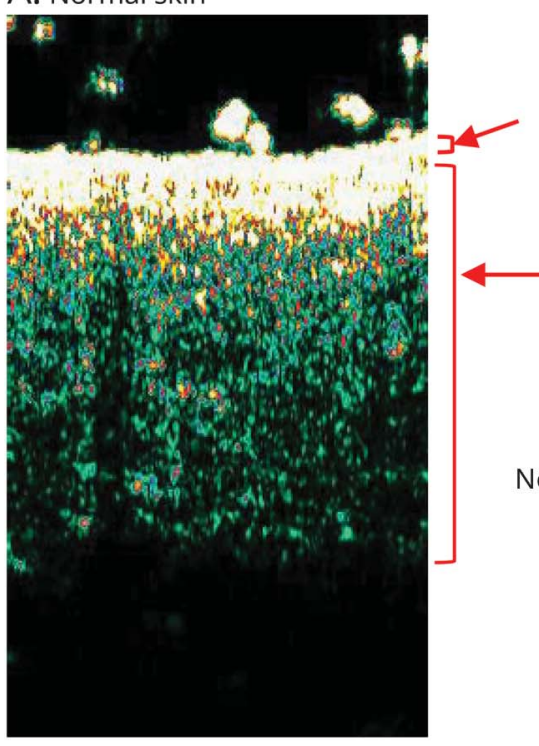

B. $\mathrm{cNF}$

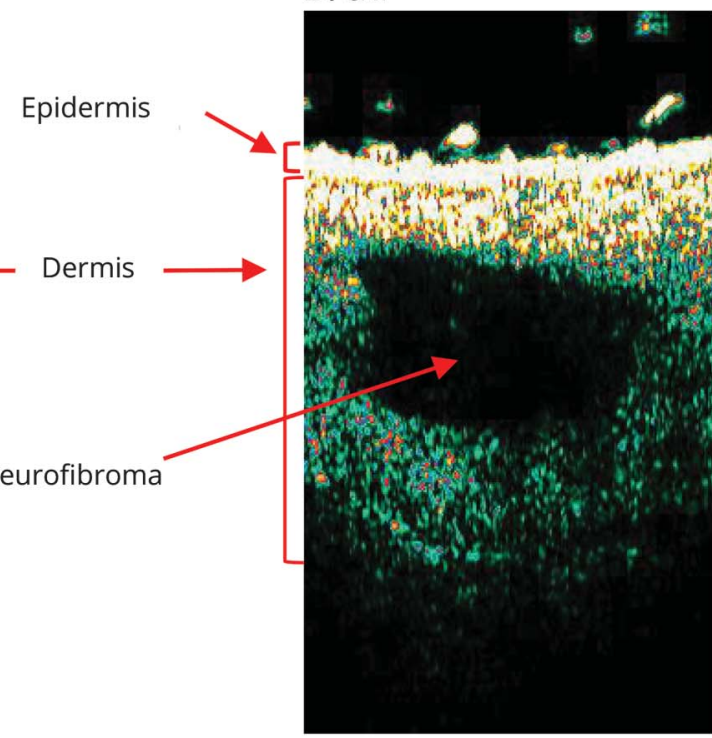

Comparison of normal skin (A) to skin with cutaneous neurofibromas (CNF) (B) using a 20-MHz transducer on the DermaScan C ultrasound. The neurofibroma is hypoechoic.

\section{Effect on patient well-being}

Patient-reported outcomes (PROs) are likely to be important in the assessment of therapeutic efficacy for $\mathrm{cNF}$ to provide information regarding the patients' perceived burden of disease, benefit of an intervention, or burden of drug toxicity. There are currently no validated PRO instruments for cNF. However, 2 PRO instruments have been studied extensively in patients with cutaneous manifestations of NF1: Short Form (SF)-36 and Skindex. ${ }^{1-3}$ SF-36 is a QoL survey to assess general physical and emotional health. Skindex is an instrument to measure the effect of skin disease on QoL, and has been validated for several dermatologic conditions including psoriasis and atopic dermatitis. Although studies evaluating cNF Skindex have consistently demonstrated that visibility of $\mathrm{cNF}$ lesions is associated with negative effects on QoL, dedicated validation for its use in studies in NF1-associated cNF is lacking.

There are other PRO measures for various dermatologic conditions based on disease-related symptoms, emotions, or function (table 2). ${ }^{18-23}$ One may consider adapting them for use in

Table 2 Patient-reported outcome (PRO) tools considered for use in clinical trials of cutaneous neurofibromas (cNF)

\begin{tabular}{|c|c|c|c|}
\hline PRO & Use & Advantages for cNF & Drawbacks for cNF \\
\hline Skindex 16 or 29 & $\begin{array}{l}\text { Assess physical and psychological } \\
\text { effects of skin conditions }\end{array}$ & Has been used in NF1 studies & $\begin{array}{l}\text { Has not been studied in NF1 } \\
\text { interventional trials }\end{array}$ \\
\hline $\begin{array}{l}\text { (Children's) } \\
\text { Dermatology Quality of } \\
\text { Life Index }\end{array}$ & $\begin{array}{l}\text { Widely used QoL index for } \\
\text { children or adults with diseases } \\
\text { affecting the skin }\end{array}$ & $\begin{array}{l}\text { Validated PROs for children and for } \\
\text { adults }\end{array}$ & Has not been used in NF1 clinical trials \\
\hline 5D itch scale & $\begin{array}{l}\text { Captures intensity and time of } \\
\text { pruritus }\end{array}$ & Symptom-specific measure & Itch is not a consistent feature in NF1 \\
\hline Visual analog scale & Widely used & $\begin{array}{l}\text { Measures a specific character or symptom } \\
\text { believed to be important in a disease (e.g., } \\
\text { pain, itch) for its overall severity }\end{array}$ & $\begin{array}{l}\text { Common uses (e.g., itch and pain) are } \\
\text { not consistent features in CNF and may } \\
\text { not reflect burden or severity in this } \\
\text { manifestation }\end{array}$ \\
\hline Numeric rating scale & Designed to rate pain & $\begin{array}{l}\text { Similar to VAS in measuring patient perception } \\
\text { of a specific symptom, but does not require } \\
\text { a written response: it can be administered } \\
\text { over the telephone }\end{array}$ & $\begin{array}{l}\text { Pain is not a common manifestation } \\
\text { for cNF in NF1 patients }\end{array}$ \\
\hline $\begin{array}{l}\text { Adult PedsQL NF1 } \\
\text { module }\end{array}$ & $\begin{array}{l}\text { Adult and pediatric specific QoL } \\
\text { measures in NF1 patients }\end{array}$ & Specific to NF1 & $\begin{array}{l}\text { May not be sensitive to specifically } \\
\text { capture the change in QoL from } \\
\text { improvement in CNF as it measures } \\
\text { multiple QoL domains in NF1 }\end{array}$ \\
\hline
\end{tabular}

Abbreviations: NF1 = neurofibromatosis 1; QoL = quality of life; VAS = visual analog scale. 
cNF trials. For instance, pruritus is an important symptom in patients with NF1 and has been shown to reduce $\mathrm{QOL}^{24}$; however, pruritus in NF1 may not be specific to cNF lesions. One study reported that pruritus was localized to sites of cNF in only $52 \%$ of the patients evaluated. ${ }^{25}$ In addition to a validated PRO measure in the NF1 population, the subgroup acknowledged the importance of availability of the instrument in multiple languages and cross-cultural relevance of its components.

\section{Biologic endpoints}

Tissue and blood biomarkers may be used as surrogates of tumor growth and might provide valuable endpoints for clinical trials. Thus far, there has been a concerted effort to identify biomarkers in plexiform neurofibromas, though progress has been limited. If pruritus could serve as a potential disease activity indicator, analytes relating to pruritus (e.g., enzymes from mast cell degranulation) might hold potential as biologic markers. However, such markers as those relating to pruritus may not be specific for cNF tumor growth, as discussed above.

\section{Important intervention considerations}

There are numerous considerations for interventions targeting $\mathrm{cNF}$ in NF1. Key factors to consider when designing clinical trials on cNF include the following:

1. Time to initiate the intervention: We do not have adequate information on the biology of the $\mathrm{cNF}$ of individual patients to confidently address this question. Despite that, a pediatric study plan should be considered early in clinical development of drugs for $\mathrm{cNF}$.

2. Eligibility for the intervention: Clinical trials should ensure diversity in enrollment with respect to age, sex, race, and geographic location, and stratify as biologically appropriate for the drug.

3. Mechanism of action of the intervention: Evaluation of mechanism of action may entail inclusion of biopsy at baseline and after the intended therapeutic window, where the collected tissue can be used to determine the effect of the intervention at the pharmacologic or molecular level.

4. Route of administration of the intervention: Risk-benefit considerations favor the use of directed therapies (topical or intralesional) when feasible as these approaches limit systemic toxicity. 4

5. Safety monitoring for administering the intervention: Clinical studies should have appropriate safety monitoring according to what is known about the intervention (e.g., from nonclinical and available clinical data) and the intended use (as treatment or prevention) so as to plan for the level of toxicity for discontinuation of intervention, dose adjustment, and rescue measures.

6. Regulatory considerations and interactions with regulatory agencies: US regulations require demonstration of both safety and substantial evidence of effectiveness under the conditions of use prescribed, recommended, or suggested in labeling. ${ }^{26}$ Demonstration that the potential benefits of the treatment outweigh the risks is necessary. Evidence of effectiveness is based on well-controlled studies of adequate design to show a significant effect on a clinically meaningful endpoint in the targeted population. For cNF, tumor shrinkage or response rate alone may not be sufficient evidence of clinical benefit. Although many oncology products have been granted accelerated approval on the basis of radiologic response rate as a surrogate endpoint that is reasonably likely to predict clinical benefit (i.e., a survival effect), the clinical relevance of achieving a partial response in a benign tumor is less certain. Objective response rates of sufficient magnitude and durability, according to a well-defined response definition specific to cNF lesions, may be considered as a primary endpoint, and incorporation of a suitable PRO, either as a co-primary or key secondary endpoint, could provide evidence of clinical benefit to patients.

\section{Discussion}

The NF1 field is at an inflection point; the level of understanding of the pathogenesis of tumors, the cells of origin, and the influence of the cellular environment has advanced in recent years. Continued progress in new technologies has provided new tools to identify and measure change in $\mathrm{cNF}$ as objective outcome measures. As scientists continue to learn more about the biology of $\mathrm{cNF}$, therapies directed at the prevention or ablation of $\mathrm{cNF}$ tumors in NF1 may be developed. The success of any development program for intervention on $\mathrm{cNF}$ in patients with NF1 will be dependent on the early and frequent interactions among regulators, NF experts, and patient groups to design and conduct appropriate trials. As noted in the opening article in this series, ${ }^{27}$ the Response Evaluation in Neurofibromatosis \& Schwannomatosis International Collaboration (ccrod.cancer. gov/confluence/display/REINS/Cutaneous+Neurofibromas) has recently formed the cNF Working Group as one step in this process. In addition, therapeutic approaches for cNF could potentially utilize benefits and incentives provided to the orphan disease community. ${ }^{4}$ Continued collaborative approaches across the broad research community will support efficient and effective clinical trial design for NF1-associated cNF lesions.

\section{Author contributions}

A. Cannon: drafting and review of the manuscript. K. Jarnagin: contributing to and review of manuscript, development of recommendations. B. Korf: review of manuscript, development of recommendations. B.C. Widemann: review of manuscript, development of recommendations, subgroup leadership. D. Casey: review of manuscript. H.-S. Ko: review of manuscript. J. Blakeley: contributing to and review of manuscript, development of recommendations. S. Verma: contributing to and review of manuscript, development of recommendations. D.C. Pichard: drafting and review of the manuscript.

\section{Acknowledgment}

The authors thank fellow cNF summit participants Richard Anderson, Naba Bora, Isaac Brownell, Sally Gottesman, 
Rhonda Jackson, Pam Knight, Robert Lavker, Salvo LaRosa, $\mathrm{Lu}$ Le, Eric Legius, Jill Morris, Michael Parides, Scott Plotkin, Vincent M. Riccardi, Ken Rudd, Marigo Stathis, Hubert Weinberg, Pierre Wolkenstein, and Pam Wolters for contributions.

\section{Study funding}

This work was supported by an agreement from The Johns Hopkins University School of Medicine and the Neurofibromatosis Therapeutic Acceleration Progam (NTAP). Its contents are solely the responsibilities of the authors and do not necessarily represent the official views of The Johns Hopkins University School of Medicine.

\section{Disclosure}

A. Cannon, K. Jarnagin, and B. Korf report no disclosures relevant to the manuscript. B. Widemann is funded through the Intramural Research Program of the NCI Center for Cancer Research and the opinions expressed here are her own and do not reflect the view of the NIH. D. Casey has nothing to disclose, and the opinions expressed here are her own and do not reflect the view of the FDA. H. Ko has nothing to disclose, and the opinions expressed here are his own and do not reflect the view of the FDA. J. Blakeley and S. Verma report no disclosures relevant to the manuscript. D. Pichard is funded through the Intramural Research Program of the NCI Center for Cancer Research, and the opinions expressed here are her own and do not reflect the view of the NIH. Go to Neurology.org/ $\mathrm{N}$ for full disclosures.

Received November 1, 2017. Accepted in final form April 13, 2018.

\section{References}

1. Wolkenstein P, Zeller J, Revuz J, Ecosse E, Leplege A. Quality-of-life impairment in neurofibromatosis type 1: a cross-sectional study of 128 cases. Arch Dermatol 2001; 137:1421-1425.

2. Kodra Y, Giustini S, Divona L, et al. Health-related quality of life in patients with neurofibromatosis type 1: a survey of 129 Italian patients. Dermatology 2009;218: 215-220.

3. Page PZ, Page GP, Ecosse E, Korf BR, Leplege A, Wolkenstein P. Impact of neurofibromatosis 1 on quality of life: a cross-sectional study of 176 American cases. Am J Med Genet A 2006;140:1893-1898.

4. Verma S, Riccardi VM, Plotkin SR. et al. Considerations for development of therapies for cutaneous neurofibroma. Neurology 2018;91:S21-S30.

5. US Food and Drug Administration. Rare diseases: common issues in drug development guidance for industry. 2015. Available at: fda.gov/downloads/Drugs/
GuidanceComplianceRegulatoryInformation/Guidances/UCM458485.pdf. Accessed February 22, 2018.

6. Cannon A, Chen MJ, Li P, et al. Cutaneous neurofibromas in neurofibromatosis type I: a quantitative natural history study. Orphanet J Rare Dis 2018;13:31.

7. Huson SM, Harper PS, Compston DA. Von Recklinghausen neurofibromatosis: a clinical and population study in south-east Wales. Brain 1988;111:1355-1381.

8. Duong TA, Bastuji-Garin S, Valeyrie-Allanore L, Sbidian E, Ferkal S, Wolkenstein P. Evolving pattern with age of cutaneous signs in neurofibromatosis type 1: a crosssectional study of 728 patients. Dermatology 2011;222:269-273.

9. Brosseau JP, Pichard DC, Legius EH. et al. The biology of cutaneous neurofibromas: consensus recommendations for setting research priorities. Neurology 2018;91: S14-S20.

10. Ortonne N, Wolkenstein P, Blakeley JO, et al Cutaneous neurofibromas: current clinical and pathologic issues. Neurology 2018;91:S5-S13.

11. Cunha KS, Rozza-de-Menezes RE, Andrade RM, et al. Validity and interexaminer reliability of a new method to quantify skin neurofibromas of neurofibromatosis 1 using paper frames. Orphanet J Rare Dis 2014;9:202.

12. Schuh S, Holmes J, Ulrich $\mathrm{M}$, et al. Imaging blood vessel morphology in skin: dynamic optical coherence tomography as a novel potential diagnostic tool in dermatology. Dermatol Ther 2017;7:187-202.

13. Raffin D, Zaragoza J, Georgescou G, et al. High-frequency ultrasound imaging for cutaneous neurofibroma in patients with neurofibromatosis type I. Eur J Dermatol 2017;27:260-265.

14. Hinz T, Ehler LK, Hornung T, et al. Preoperative characterization of basal cell carcinoma comparing tumour thickness measurement by optical coherence tomography, 20-MHz ultrasound and histopathology. Acta Derm Venereol 2012;92: $132-137$.

15. Zarchi K, Wortsman X, Jemec GB. Ultrasound as a diagnostic aid in identifying neurofibromas. Pediatr Dermatol 2014;31:535-537.

16. Futamura M, Leshem YA, Thomas KS, Nankervis H, Williams HC, Simpson EL. A systematic review of investigator global assessment (IGA) in atopic dermatitis (AD) trials: many options, no standards. J Am Acad Dermatol 2016;74:288-294.

17. Ng ZY, Kang GC, Chang CS, Por YC. Efficacy of topical timolol as primary monotherapy in cutaneous facial infantile hemangiomas. J Craniofac Surg 2016;27: e516-e520.

18. Chren MM, Lasek RJ, Quinn LM, Mostow EN, Zyzanski SJ. Skindex, a quality-of-life measure for patients with skin disease: reliability, validity, and responsiveness. J Invest Dermatol 1996;107:707-713.

19. Carlin CS, Feldman SR, Krueger JG, Menter A, Krueger GG. A 50\% reduction in the psoriasis area and severity index (PASI 50) is a clinically significant endpoint in the assessment of psoriasis. J Am Acad Dermatol 2004;50:859-866.

20. Langley RG, Ellis CN. Evaluating psoriasis with psoriasis area and severity index, psoriasis global assessment, and lattice system physician's global assessment. J Am Acad Dermatol 2004;51:563-569.

21. Stander S, Augustin M, Reich A, et al. Pruritus assessment in clinical trials: consensus recommendations from the international forum for the study of itch (IFSI) special interest group scoring itch in clinical trials. Acta Derm Venereol 2013;93: 509-514.

22. Elman S, Hynan LS, Gabriel V, Mayo MJ. The 5-D itch scale: a new measure of pruritus. Br J Dermatol 2010;162:587-593.

23. Furue M, Ebata T, Ikoma A, et al. Verbalizing extremes of the visual analogue scale for pruritus: a consensus statement. Acta Derm Venereol 2013;93:214-215.

24. Hanemann CO, Blakeley JO, Nunes FP, et al. Current status and recommendations for biomarkers and biobanking in neurofibromatosis. Neurology 2016;87:S40-S48.

25. Brenaut E, Nizery-Guermeur C, Audebert-Bellanger S, et al. Clinical characteristics of pruritus in neurofibromatosis 1. Acta Derm Venereol 2016;96:398-399.

26. US Food and Drug Administration. CFR: Code of Federal Regulations title 21. 2017. Available at: ecfr.gov/cgi-bin/text-idx?SID=bd96965aea2478463dfb4edb79e5269e\& $\mathrm{mc}=$ true\&node=se21.4.201_156\&rgn=div8. Accessed February 22, 2018.

27. Blakeley JO, Wolkenstein P, Widemann BC, et al. Creating a comprehensive research strategy for cutaneous neurofibromas. Neurology 2018;91:S1-S4. 


\title{
Neurology
}

\author{
Clinical trial design for cutaneous neurofibromas \\ Ashley Cannon, Kurt Jarnagin, Bruce Korf, et al. \\ Neurology 2018;91;S31-S37 \\ DOI 10.1212/WNL.0000000000005790
}

This information is current as of July 9, 2018

\section{Updated Information \& Services}

\section{References}

Permissions \& Licensing

\section{Reprints}

including high resolution figures, can be found at: http://n.neurology.org/content/91/2_Supplement_1/S31.full

This article cites 25 articles, 0 of which you can access for free at: http://n.neurology.org/content/91/2_Supplement_1/S31.full\#ref-list-1

Information about reproducing this article in parts (figures,tables) or in its entirety can be found online at:

http://www.neurology.org/about/about_the_journal\#permissions

Information about ordering reprints can be found online:

http://n.neurology.org/subscribers/advertise

Neurology ${ }^{\circledR}$ is the official journal of the American Academy of Neurology. Published continuously since 1951, it is now a weekly with 48 issues per year. Copyright @ 2018 The Author(s). Published by Wolters Kluwer Health, Inc. on behalf of the American Academy of Neurology.. All rights reserved. Print ISSN: 0028-3878. Online ISSN: 1526-632X.

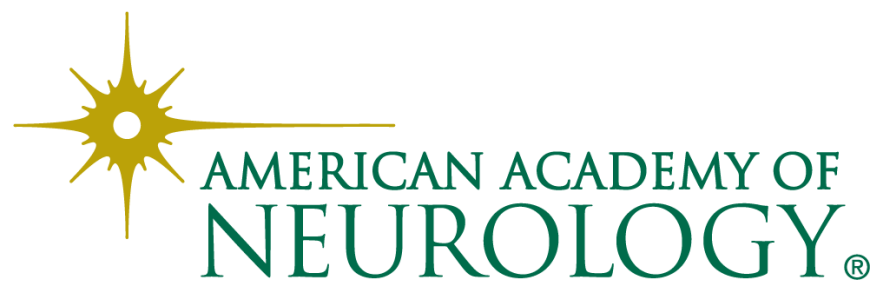

